\title{
Cyclic heat load testing of improved CFC/Cu bonding for the W 7-X divertor targets
}

\author{
H. Greuner ${ }^{\text {a, }}{ }^{*}$, B. Böswirth ${ }^{\text {a }}$, J. Boscary ${ }^{\text {a }}$, P. Chaudhuri ${ }^{\text {b }}$, J. Schlosser ${ }^{c}$, \\ T. Friedrich ${ }^{d}$, A. Plankensteiner d, R. Tivey ${ }^{a}$ \\ a Max-Planck-Institut für Plasmaphysik, EURATOM Association, 85741 Garching, Germany \\ ${ }^{b}$ Institute for Plasma Research, Bhat, Gandhinagar-382 428, India \\ ${ }^{c}$ CEA Cadarache, Euratom Association, F-13108 St Paul-lez-Durance, France \\ ${ }^{d}$ PLANSEE SE, Innovation Services, 6600 Reutte, Austria
}

\begin{abstract}
Extensive high heat flux cycling testing of pre-series targets was performed in the neutral beam facility GLADIS to establish the industrial process for the manufacturing of 890 targets, which will be needed for the installation of the WENDELSTEIN 7-X divertor. The targets are manufactured of flat tiles of CFC NB31 as plasma facing material bonded by an Active Metal Casting copper interlayer onto a water-cooled CuCrZr structure. Based on the results of the 3D thermo-mechanical FEM analysis of the CFC/Cu interface, an additional set of 17 full-scale pre-series elements including three design variations was manufactured by PLANSEE SE. The insertion of an additional plastically compliant copper interlayer between the cooling structure and the Active Metal Casting interlayer showed the best results. No critical tile detachment was observed during $>5000$ cycles at $10 \mathrm{MW} / \mathrm{m}^{2}$. These results demonstrated the sufficient life time of the component for the expected heat load in operation.
\end{abstract}

\begin{abstract}
1. Introduction
The aim of the extensive high heat flux (HHF) test campaigns was to establish the industrial process for the manufacturing of 890 targets, which will be needed for the installation of the $19 \mathrm{~m} 2$ highly loaded divertor area in WENDELSTEIN 7-X (W7-X) [1]. The target design is based on flat tiles made of CFC NB31 [2-4] as plasma facing material bonded by Active Metal Casting (AMC) [5] onto a water-cooled CuCrZr structure [6]. The excellent heat removal capability was demonstrated in previous test campaigns of more than 30 full-scale pre-series elements $[7,8]$. No large detachment or loss of CFC tiles occurred during previous cyclic loading tests performed in the neutral beam facility GLADIS [9], but growing local degradation of bonding at the free edges of several CFC tiles was observed. Therefore a detailed nonlinear thermo-mechanical FEM analysis of the $\mathrm{CFC} / \mathrm{Cu}$ bonding system was carried out with a view to achieving a reduction of the stress at this interface [10]. Based on the results of the analysis, 17 additional pre-series elements with different bonding options were manufactured (Fig. 1). Following the same approach as for the previous preseries elements, the performance of these elements was assessed by HHF cyclic testing in GLADIS in order to select the option for the series manufacturing. The investigation was focused on the analysis of crack propagation during cycling up to $>5000$ pulses in respect of the prediction of expected operational life time.
\end{abstract}

* Corresponding author.

E-mail address: henri.greuner@ipp.mpg.de (H. Greuner).

\section{Results of thermo-mechanical FEM analysis of $\mathrm{CFC} / \mathrm{Cu}$ bonging variants}

The temporal and spatial evolution of temperatures, stresses and strains and corresponding measures are calculated for the three different target design variants and are evaluated for the CFC sections in terms of maximum principal stresses,

for the metallic sections in terms of equivalent plastic strains, and for the CFC/AMC-interface in terms of the normal component of the interfacial tractions. These solution variables are normalized with those obtained for the initial design to allow a better comparability of the variants. The insertion of a plastically compliant Cu-interlayer between AMC and cooling structure (so-called 'bi-layer') shows a beneficial effect on the stresses and strains in both the CFC and metallic sections. The most favorable options to reduce the stress at the free edge of CFC/Cu-interface are compared in Table 1. Based on the results of these FEM simulations and in respect to a cost effective series manufacturing, elements for three most promising technology options have been fabricated.

\section{Variants of manufactured CFC/Cu-bonding}

The initial CFC tile bonding was done with a $3 \mathrm{~mm}$ thick AMC interlayer. CFC tiles which have typical dimensions of $25 \mathrm{~mm}$ length, $55 \mathrm{~mm}$ width and $8 \mathrm{~mm}$ thickness were bonded onto the cooling structure with the highest thermal conductivity (ex-pitch fibres) normal to the cooling structure, ex-PAN fibres across theelement and needling direction along the element [11]. Three new variants of CFC/Cu bonding have been investigated: 
- $\quad$ Option 1: $3 \mathrm{~mm}$ thick bi-layer, insertion of a $2.6 \mathrm{~mm} \mathrm{Cu}$ interlayer between cooling structure and AMC by hot isostatic pressing (HIP) after the AMC process.

- Option 2: reduction of the size of the CFC tiles to $1 / 2$ of the target width with AMC (option 2a) or bi-layer (option $2 \mathrm{~b}$ ) bond, or $1 / 3$ of the target width with AMC (option 2c) or bi-layer (option $2 \mathrm{~d}$ ) bond.

- Option 3: tile size similar to option 2 and change of the orientation of CFC tiles with $90^{\circ}$ in-plane rotation of the ex-PAN fiber planes.

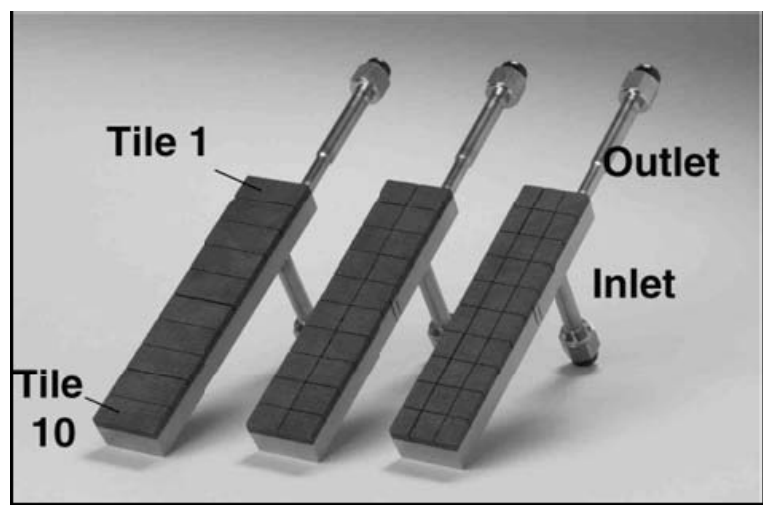

Fig. 1. Target elements of the pre-series III manufactured by PLANSEE SE: design with one, two or three tiles across the element. Flat CFC NB31tiles with a thickness of $8 \mathrm{~mm}$ are bonded onto CuCrZr cooling structures (250 mm length, 57 $\mathrm{mm}$ width). The four cooling channels are equipped with swirl tapes. Tile numbering starts at the outlet side.

\section{High heat flux loading}

The following experiments were performed with $10 \mathrm{~s}$ pulses of $10 \mathrm{MW} / \mathrm{m}^{2}$ :

- All 17 elements for 100 cycles to define a preliminary acceptance reference.

- Four elements for 1000 cycles per tile (two elements of option 1 and one element of option 2 and 3 , respectively).

- $\quad$ Two elements on the preferred option 1 were exposed to $>5000$ cycles to study the crack propagation for loads between 7- $10 \mathrm{MW} / \mathrm{mm}^{2}$.

\subsection{Heat loading conditions}

The test conditions were similar to the W7-X full power operating requirements: $8 \mathrm{~m} / \mathrm{s}$ cooling water velocity, $\sim 20^{\circ} \mathrm{C}$ inlet temperature and $1 \mathrm{MPa}$ static pressure. The target elements were mounted perpendicular to the ion beam axis in the GLADIS facility. Three beam positions were used to test the targets with a uniform heat load of $85-100 \%$ of the central heat flux on each tile. The heat load on tile number 1 and 10 (see Fig. 1) was reduced to $75 \%$ of the nominal heat flux. These loading conditions are similar to the expected load during full power operation in W7-X. The power density at the target position was periodically measured and checked with a linearly movable calorimeter during the test campaign. More details of the loading conditions in GLADIS are described in the reference [8]. A pulse length of $10 \mathrm{~s}$ for cycling was applied because the target achieved the thermal equilibrium after $7 \mathrm{~s}$ of loading. For the surface temperature measurements an IR camera plus one- and two-colour pyrometers were used. The component temperature was measured with thermocouples located in the cooling structure and the CFC tiles. A detailed description of the beam profiles, the used diagnostics and the thermocouple positions is given in [7].

\subsection{Thermal FEM simulation of CFC bonding defects}

Simulations were performed using the ANSYS ${ }^{\circledR}$ code in order to correlate the type and size of defects at the interface $\mathrm{CFC} / \mathrm{Cu}$ to an increase of the surface temperatures during 10 $\mathrm{MW} / \mathrm{m} 2$ steady-state load. A de-bonding located at the outer corner of CFC/AMC edge, or enclosed in the outer edge and a completely de-bonded outer edge of a CFC tile (band defect) were simulated considering the effect of thermal radiation of the CFC surface (Fig. 2). The assumption of a de-bonded area is based on an open crack without thermal contact. The calculation shows a reliable detection limit of about $3 \times 3 \mathrm{~mm}^{2}$ for a corner-, about $3 \times 4 \mathrm{~mm}^{2}$ for a defect enclosed in the outer edge and $30 \mathrm{~mm}^{2}(1.2 \mathrm{~mm}$ width) for the band defect.

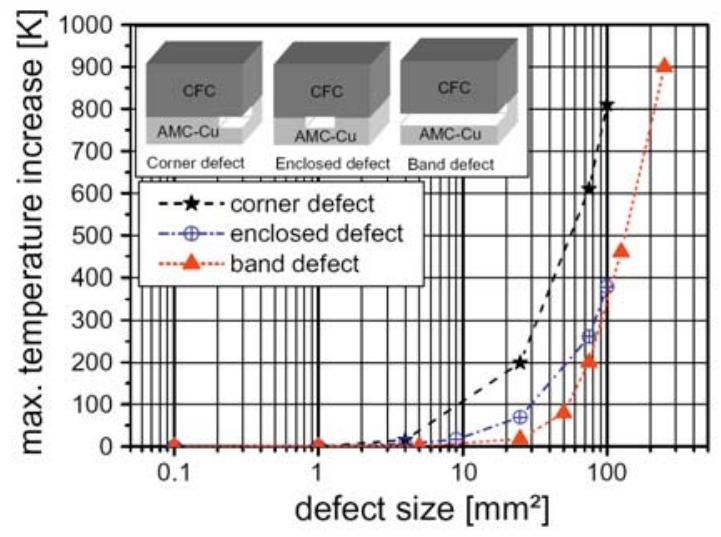

Fig. 2. Expected increase of the maximal CFC temperature for the W7-X standard geometry and $10 \mathrm{MW} / \mathrm{m} 2$ load. The surface temperature increase of a defect at the interface CFC/Cu was simulated with a $0.25 \mathrm{~mm}$ thick gap at this location. The length of a band defect, $25 \mathrm{~mm}$, corresponds to the standard size of the tile along the element.

\subsection{Results of low cycle fatigue loading of $10.5 \mathrm{MW} / \mathrm{m}^{2}$}

The IR observation during the cyclic loading showed a partial de-bonding of the outer edges of some tiles, especially for tiles $5-10$. This is the consequence of a significant temperature increase of cooling structure resulting in higher stress level of CFC/Cu bonding. This increase of 50-130 K was caused by a growing failure ofinner central welding. The opening of the welding during heat load resulted in a bypass flow and reduction of heat transfer. For the in/ outlet part (covered with tiles 1-4), the inner geometry avoided a significant bypass flow and ensured a sufficient heat transfer. A secondary effect of heat transfer reduction was observed due to a slowly growing formation of deposits on the inner highly heat loaded part of the cooling channel. Meanwhile, both problems were solved and experimentally confirmed. A geometrical modification of the inner weld ensures the thermo-mechanical stiffness of the component. An ion exchanger was installed in the coolant loop of GLADIS to meet always the requirements of high purity water. A good assessment of the CFC/Cu bonding quality is given by IR analysis of local temperature differences between tile centre Tcentre and the outer edges Tedge in the steady-state condition for each pulse. The evolution of temperature differences 


\begin{tabular}{|c|c|c|c|c|}
\hline $\begin{array}{l}\text { Variant, type of } \\
\text { bonding }\end{array}$ & $\begin{array}{l}\text { CFC tile size (Referring to } \\
57 \mathrm{~mm} \text { target width) }\end{array}$ & $\begin{array}{l}\text { Normalized max. principal } \\
\text { stress in CFC \% }\end{array}$ & $\begin{array}{l}\text { Normalized max. equiv. } \\
\text { plastic strain in AMC-Cu \% }\end{array}$ & $\begin{array}{l}\text { Normalized max. contact } \\
\text { tension at CFC/AMC \% }\end{array}$ \\
\hline $\begin{array}{l}\text { (1) Initial design } \\
\text { CFC/AMC }\end{array}$ & Full width & 100 & 100 & 100 \\
\hline $\begin{array}{l}\text { (2) } \text { CFC } 90^{\circ} \text { rotated } \\
\text { bi-layer }\end{array}$ & Full width & 61.5 & 43.3 & 48.2 \\
\hline $\begin{array}{l}\text { (3) Option } 1 \mathrm{CFC} / \\
\text { bi-layer }\end{array}$ & Full width & 59.8 & 54.8 & 45.4 \\
\hline $\begin{array}{l}\text { (4) Option 2a CFC/ } \\
\text { AMC }\end{array}$ & $1 / 2$ width & 96.4 & 87.2 & 93.7 \\
\hline $\begin{array}{l}\text { (5) Option } 2 \mathrm{~b} \mathrm{CFC/} \\
\text { bi-layer }\end{array}$ & $1 / 2$ width & 58.8 & 32.8 & 39.8 \\
\hline $\begin{array}{l}\text { (6) Option 2c CFC/ } \\
\text { AMC }\end{array}$ & $1 / 3$ width & 94.5 & 83.1 & 98.7 \\
\hline $\begin{array}{l}\text { (7) Option } 2 \mathrm{~d} \mathrm{CFC/} \\
\text { bi-layer }\end{array}$ & $1 / 3$ width & 58.6 & 29.8 & 45.9 \\
\hline
\end{tabular}

Table 1: Predicted stress and strain measures for tested CFC/Cu bonding variants. Variants of bi-layer type show significant lower stresses and strains compared to the initial design with AMC only.

$$
\Delta T_{N}=\left(T_{\text {edge }}-T_{\text {centre }}\right)_{N}-\left(T_{\text {edge }}-T_{\text {centre }}\right)_{1}
$$

after $\mathrm{N}$ pulses allowed a detection of growing defects and reduces the influence of CFC inhomogeneities and changes in IR-window transmission to the interpretation. A preliminary assumption of a temperature increase $\Delta T_{N} \leq 50 \mathrm{~K}$ for an adequate, up to $\Delta \mathrm{T}_{\mathrm{N}}=50-75 \mathrm{~K}$ for a questionable and $\Delta \mathrm{T}_{\mathrm{N}}>$ $75 \mathrm{~K}$ for an inadequate bonding is given in Table 2 in \% of tiles.

\begin{tabular}{llll}
\hline CFC/Cu bonding & $\Delta T_{100} \leqslant 50 \mathrm{~K}(\%)$ & $\Delta T_{100}=50-75 \mathrm{~K}(\%)$ & $\Delta T_{100}>75 \mathrm{~K}(\%)$ \\
\hline Option 1, 37 tiles & 84 & 14 & 2 \\
Option 2, 48 tiles & 90 & 10 & \\
Option 3, 176 tiles & 87 & 7 & 6 \\
\hline
\end{tabular}

Table 2 Summary of growing local temperature increase between CFC tile centre and outer edges after $N=100$ loading pulses.

\subsection{0 cycles of $10.5 \mathrm{MW} / \mathrm{m}^{2}$}

Tiles 1-4 showed low progressive damage for all elements: a maximal local temperature increase $<200 \mathrm{~K}$ of 23 tiles indicated only small corner defects $<25 \mathrm{~mm}^{2}$. Only for one tile number 4 a slowly growing larger band defect of $\sim 3 \mathrm{~mm}$ width was observed, but tiles number 4 were loaded with 2000 cycles overall due to the beam arrangement. In contrast to these results, the tiles number $5-10$ were more damaged. The criterion $\Delta T_{1000}$ indicated for 15 tiles $>500 \mathrm{~K}$, for 11 tiles $201-500 \mathrm{~K}$ and for 10 tiles $\leq 200 \mathrm{~K}$. The results of options with smaller tiles did not justify the higher effort in manufacturing and quality assurance for such elements.

\subsection{Results of extended heat loading up to 5000 cycles}

Finally, the cycling of two elements (option 1) was extended to $>5000$ pulses on tiles number $1-3$ and tiles 4 and 5 to $>6000$ pulses to study the evolution of bonding defects depending on cycle number and local heat load. Tiles 2-4 were loaded with $10 \mathrm{MW} / \mathrm{m}^{2}$ on average, tiles 1,5 with load profile between 9-7.5 MW/m². The comparison between the predicted (Fig. 2) and the IR-measured maximal surface temperature increase allowed to estimate the de-bonding size. Fig. 3 shows the expected defect propagation for the tested elements. Six defects, D1-D6, were identified as four slowly growing corner and one larger band defect. An already existing de-bonding (D3) of $65 \mathrm{~mm} 2$ did not increase for cyclic heat load of $7.2 \mathrm{MW} / \mathrm{m}^{2}$. The maximal temperature of $1755^{\circ} \mathrm{C}$ of the largest failure after 5000 cycles should be acceptable for operation in W7-X until the regular next opening. This growing band defect was clearly detected in an early stage. The slow increase during $10 \mathrm{MW} / \mathrm{m}^{2}$ cycling confirmed the effect of stress reduction due to the bi-layer. No significant progress of existing de-bonding was observed for heat loads $<9 \mathrm{MW} / \mathrm{m}^{2}$ on the two tested elements. The results of metallographical analysis of 7 target cross-sections showed:

- $\quad$ All identified growing hot spots were confirmed as $\mathrm{CFC} / \mathrm{Cu}$ de-bonding on the free edge.

- The predicted de-bonding sizes of small hot spots were confirmed. A detection limit of $\geq 3 \times 3 \mathrm{~mm}^{2}$ can be confirmed for the IR observation during heat loading.

- $\quad$ Concerning the predictions of de-bonded area for a band defect at the outer edge, the microscopically measured de-bonding length (along the width of element) was longer than expected. The open crack ended in a fissure with a remaining partial thermal contact.

- No defects were observed at the $\mathrm{AMC} / \mathrm{Cu}$ bi-layer bonding as illustrated in Fig. 4.

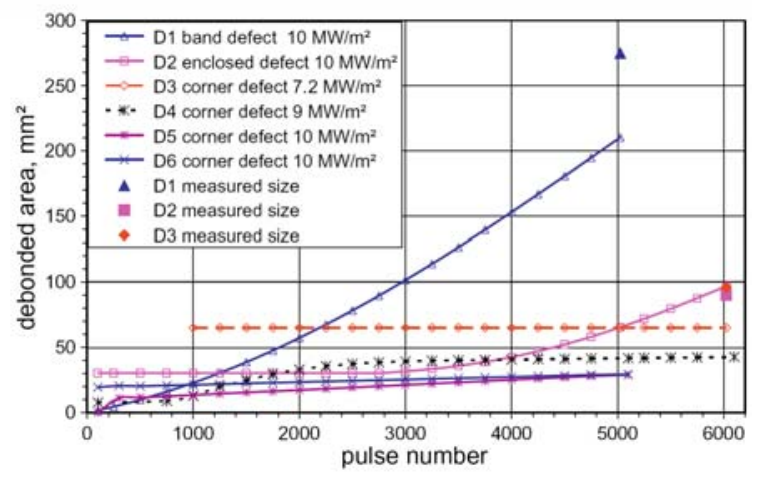

Fig. 3. Predicted growing of $\mathrm{CFC} / \mathrm{Cu}$ de-bonding versus cycle number. The size of defects D1-D3 was microscopically measured after cycling. 


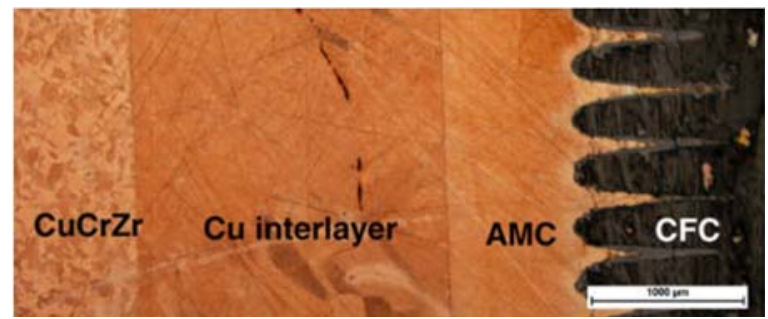

Fig. 4. Cross-section of CFC/Cu bonding of bi-layer type. The image clearly shows the good joining quality of the Cuinterlayer.

In Fig. 5 is shown the $5 \mathrm{~mm}$ width of defect D2. The corresponding de-bonding length of $18 \mathrm{~mm}$ was measured at the outer edge of the target before.

\section{Conclusions}

Pre-series activities resulted in a significant improvement of thereliability of the improved bonding between CFC tiles and $\mathrm{CuCrZr}$ heat sink. The insertion of an additional compliant $\mathrm{Cu}$ interlayer resulted in a strong reduction of stresses and strains in the CFC/Cu interface. Extensive HHF testing in GLADIS confirmed the benefit of AMC /Cu bi-layer at this interface, which was predicted by FEM analyses. Test campaigns of more than 5000 cycles at $10 \mathrm{MW} / \mathrm{m}^{2}$ demonstrated the improved reliability of target elements made of full size CFC tiles and bi-layers. A reduced crack propagation was observed at the $\mathrm{CFC} / \mathrm{Cu}$-interface due to the insertion of an additional Cu-interlayer.

HHF test results of options two and three did not show significant benefits of the tile size reduction or of the in-plane rotation of CFC fibre orientation. As result, option one is the preferred solution according to experimental examinations and to manufacturing costs.

The predicted size of $\mathrm{CFC} / \mathrm{Cu}$ de-bonding corresponding to the IR measured surface temperature increase during loading was metallographically verified. HHF testing also proved that no sudden loss of tiles must be expected during operation in W7-X. It should allow the operation to continue with damaged targets until the next regular opening of the machine.

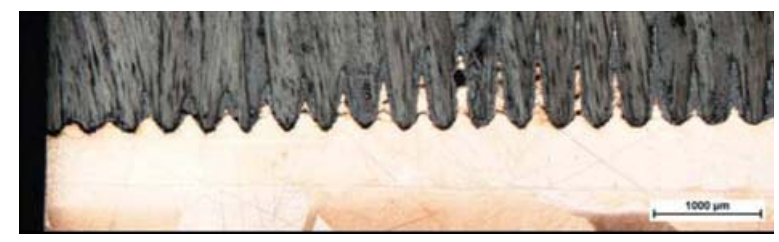

Fig. 5. Small de-bonding of outer edge after 6000 cycles IR detected before. The length of de-bonding is $5 \mathrm{~mm}$. The scale represents $1000 \mu \mathrm{m}$.

\section{References}

[1] H. Renner et al., Nucl. Fus. 40 (2000) 1083.

[2] M. Merola, C.H. Wu, Phys. Scripta T111 (2004) 152.

[3] A.T. Peacock, M. Merola, M.A. Pick, R. Tivey, Phys. Scripta T128 (2007) 23.

[4] G. Pintsuk et al., Phys. Scripta T128 (2007) 66.

[5] Patent EP 0663670 and Patent TO2003A000795.

[6] J. Boscary, H. Greuner, B. Mendelevitch, B. Schedler, K. Scheiber, J. Schlosser, B. Streibl, Fus. Eng. Des. 75-79 (2005) 451.

[7] H. Greuner, B. Böswirth, J. Boscary, A. Leuprecht, A. Plankensteiner, Phys. Scripta T128 (2007) 218.

[8] H. Greuner, B. Boeswirth, J. Boscary, A. Plankensteiner, B. Schedler, Fus. Eng. Des. 82 (2007) 1713.

[9] H. Greuner et al., Fus. Eng. Des. 75-79 (2005) 345.

[10] A. Plankensteiner, A. Leuprecht, B. Schelder, K.H. Scheiber, H. Greuner, Fus. Eng. Des. 82 (2007) 1813.

[11] J. Boscary, B. Böswirth, H. Greuner, P. Grigull, M. Missirlian, A. Plankensteiner, B. Schedler, T. Friedrich, J. Schlosser, B. Streibl, H. Traxler, Phys. Scripta T128 (2007) 195. 